\title{
Articles
}

\section{Conformational Isomorphism of Organic Crystals: Racemic and Homochiral Atenolol}

\author{
R. A. Esteves de Castro ${ }^{\ddagger}$ João Canotilho, ${ }^{*} \neq$ Rui M. Barbosa, ${ }^{\ddagger}$ M. Ramos Silva, ${ }^{\#}$ \\ A. Matos Beja, ${ }^{\#}$ J. A. Paixão, ${ }^{\#}$ and J. Simões Redinha ${ }^{\dagger}$ \\ Department of Chemistry, Rua Larga 3004-535, University of Coimbra, Portugal, Faculty of \\ Pharmacy, Rua do Norte 3000-295, University of Coimbra, Portugal, and CEMDRX, Department of \\ Physics, Rua Larga 3004-516, University of Coimbra, Portugal
}

Received April 3, 2006; Revised Manuscript Received October 16, 2006

\begin{abstract}
X-ray diffraction analysis of $(R, S)$ - and $S$-atenolol crystalline forms was performed. The crystals studied were grown from evaporation of an ethanol/water solution. $(R, S)$-Atenolol crystallizes in the centrosymmetric space group $C 2 / c$, and $S$-atenolol crystallizes in a noncentrosymmetric space group $C 2$. There is one symmetry independent molecule in $(R, S)$-atenolol crystals and two symmetry independent molecules in $S$-atenolol. However, due to disorder, two different molecular conformations were identified in the $(R, S)$-atenolol, and three different conformations were isolated in $S$-atenolol. Flexibility of molecular segments of the carbon chain is seen in conformational isomorphism and in the atomic position uncertainty. The molecular conformations given by X-ray diffraction were fully relaxed at the $\mathrm{HF} / 6-31 \mathrm{G}^{*}$ level of theory. The optimized structure was used as reference in comparison with molecular conformation in the solid state.
\end{abstract}

\section{Introduction}

Since bioavailability and properties related to formulation depend on the crystalline structure, its knowledge is essential in pharmaceutical technology. ${ }^{1-3}$ Single-crystal X-ray diffraction is the most useful technique available for obtaining comprehensive information on the molecular and crystal structures. The problem that has to be overcome is the preparation of single crystals suitable for study by this technique.

A factor often associated with the difficulties in the crystallization of organic compounds is the conformational diversity in solution. Molecules of large size exhibit numerous conformational possibilities giving rise to minuscule crystal size or amorphous solid materials. ${ }^{4,5}$ Single-crystal growth is often a true challenge combining science and art and even a little luck, hence the lack of data about the structure of many organic compounds.

This work concerns the study of the structure of atenolol, 4-[2'-hydroxy-3'-[(1-methylethyl)amino]propoxy]-benzeneacetamide, a compound widely prescribed in medicine as a cardioselective $\beta_{1}$-adrenergic blocker. As a best-selling drug, ${ }^{6,7}$ atenolol has become the focus of active research. Nevertheless, its crystal structure has not yet been reported, which is a serious obstacle to understanding its properties from both the theoretical and the practical point of view.

\footnotetext{
* To whom correspondence should be addressed. E-mail: jcano@ci.uc.pt.

$\dagger$ Department of Chemistry.

Faculty of Pharmacy.

\# CEMDRX, Department of Physics.
}

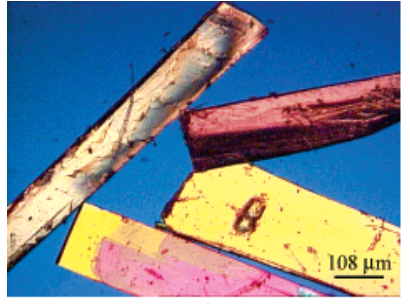

a)

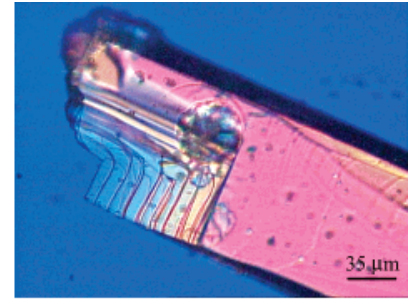

b)
Figure 1. (a) Photomicrograph with polarized light of $(R, S)$-atenolol crystals $(50 \times)$; (b) detail of crystal aggregates $(200 \times)$.

The atenolol molecule has a chiral center giving rise to $R$ and $S$ enantiomers, which have different biological activities. ${ }^{8}$ This paper deals with the structure of the racemic and homochiral forms, studied by X-ray diffraction and molecular modeling.

\section{Experimental Procedures}

$(R, S)$-Atenolol purchased from Mikromol Gmbh was the original substance used in this research. The product came with a quality control certificate with a specification of $99.76 \mathrm{~mol}$ percent pure. The degree of purity was based on NMR, HPLC, and acid-base titration tests. $S$-(-)-Atenolol was supplied by Sigma-Aldrich as $99 \%$ pure. HPLC did not reveal any impurity. The value found for $[\alpha]_{\mathrm{D}}^{25}$ was $-16.2^{\circ}(C$ $=1$ in $1 \mathrm{~N} \mathrm{HCl}$ ).

Single crystals of both compounds were obtained by slow evaporation of the solvent from solutions of $(R, S)$-atenolol or $S$-atenolol in ethanol/water. A 0.1 M solution of atenolol in 20:80 volume percent 
Table 1. Crystal Data and Structure Refinement Parameters for $(R, S)$-Atenolol and $S$-Atenolol

\begin{tabular}{|c|c|c|}
\hline & $(R, S)$-atenolol & $S$-atenolol \\
\hline empirical formula & $\mathrm{C}_{14} \mathrm{H}_{22} \mathrm{~N}_{2} \mathrm{O}_{3}$ & $\mathrm{C}_{14} \mathrm{H}_{22} \mathrm{~N}_{2} \mathrm{O}_{3}$ \\
\hline formula weight & 266.34 & 266.34 \\
\hline temperature/K & 293(2) & 293(2) \\
\hline wavelength $/ \AA$ & 1.54180 & 1.54180 \\
\hline crystal system & monoclinic & monoclinic \\
\hline space group & $C 2 / c$ & $C 2$ \\
\hline$a / \AA ̊$ & $55.83(3)$ & $54.43(3)$ \\
\hline$b / \AA ̊ ̊$ & $5.559(3)$ & $5.712(3)$ \\
\hline$c / \AA$ & $9.734(2)$ & $9.676(2)$ \\
\hline$\beta /^{\circ}$ & $100.042(6)$ & $99.510(6)$ \\
\hline volume $/ \AA^{3}$ & $2975(2)$ & $2967(2)$ \\
\hline$Z$ & 8 & 8 \\
\hline calculated density $/ \mathrm{g} \mathrm{cm}^{-3}$ & 1.189 & 1.192 \\
\hline absorption coefficient $/ \mathrm{mm}^{-1}$ & 0.681 & 0.682 \\
\hline$F_{\mathrm{OOO}}$ & 1152 & 1152 \\
\hline crystal size/mm & $0.50 \times 0.37 \times 0.07$ & $0.42 \times 0.36 \times 0.07$ \\
\hline$\theta$ range for data collection ${ }^{\circ}$ & $3.2-72.6$ & $4.6-73.3$ \\
\hline index ranges & $-66<h<67,-6<k<6,-12<l<12$ & $-66<h<60,-7<k<7,-11<l<11$ \\
\hline reflections collected/unique & $6262 / 2919[R(\mathrm{int})=0.052]$ & $11689 / 5474[R(\mathrm{int})=0.044]$ \\
\hline completeness to $\theta_{\max }$ & $99.0 \%$ & $97.3 \%$ \\
\hline refinement method & full-matrix least-squares on $F^{2}$ & full-matrix least-squares on $F^{2}$ \\
\hline data/restraints/parameters & $2919 / 2 / 174$ & $5474 / 1 / 338$ \\
\hline goodness-of-fit on $F^{2}$ & 1.803 & 1.055 \\
\hline final $R$ indices $[I>2 \sigma(I)]$ & $\mathrm{R} 1=0.1296 \mathrm{wR} 2=0.3867$ & $\mathrm{R} 1=0.0746 \mathrm{wR} 2=0.1891$ \\
\hline$R$ indices (all data) & $\mathrm{R} 1=0.1505 \mathrm{wR} 2=0.4145$ & $\mathrm{R} 1=0.0990 \mathrm{wR} 2=0.2097$ \\
\hline largest diff peak and hole /e $\AA^{-3}$ & 0.78 and -0.84 & 0.68 and -0.39 \\
\hline
\end{tabular}

ethanol/water was evaporated at $25^{\circ} \mathrm{C}$ from a narrow neck conical flask. The crystalline solid was dried at $40{ }^{\circ} \mathrm{C}$ and kept in a desiccator. When the sample was examined by polarized light microscopy, optically anisotropic laminate crystals were observed (Figure 1). Identical crystalline habit is observed for both racemic and enantiomeric forms.

Diffraction measurements of $(R, S)$-atenolol were carried out by $\mathrm{Cu}$ $\mathrm{K} \alpha$ radiation using a Mach-3 diffractometer equipped with a conventional detector. Data reduction was performed with HELENA. ${ }^{9}$ For $S$-atenolol, a similar diffractometer was used, equipped with an area detector. Data reduction was performed with Bruker SAINT. ${ }^{10}$ Lorenz and polarization corrections were applied to both data sets. The structures were solved with direct methods using the SHELXS-97 program ${ }^{11}$ and refined on $F^{2}$ 's by full-matrix least-squares with the SHELXL-97 program. ${ }^{11}$ Anisotropic displacement parameters for nonhydrogen atoms were applied with the exception of terminal $\mathrm{C}(13)$ and $\mathrm{C}(14)$ for $(R, S)$ and of those atoms in the disordered part of one of the molecules for $S$-atenolol. Hydrogen atoms were placed at calculated positions and refined with isotropic parameters as riding mobile atoms, except for those of the disordered methyl groups, which were not included in the refinement.

For $(R, S)$-atenolol the bond distances, $\mathrm{C}(12)-\mathrm{C}(13), \mathrm{C}(12)-\mathrm{C}(14)$, $\mathrm{C}(10)-\mathrm{C}(11)$, and $\mathrm{N}(2)-\mathrm{C}(11)$ were constrained to be $1.5,1.5,1.5$, and $1.3 \AA$, respectively, during the refinement.

Space groups were assigned using PLATON, and the systematic absences were carefully checked, namely, the $h 01$ reflections, confirming the assignment of $C 2$ to the structure of $S$-atenolol.

The structure of the $(R, S)$ - and $S$-atenolol, retaining the solid-state conformations shown by X-ray, was fully optimized at HF/6-31G* level of theory using the Gaussian 98 convergence criteria. ${ }^{12}$

\section{Results and Discussion}

X-ray Diffraction. The crystal data and details concerning data collection and structure refinement are given in Table 1 . The ORTEPII ${ }^{13}$ drawings of $(R, S)$ and $S$-atenolol are shown in Figure 2.

$(R, S)$-Atenolol crystallizes in the centrosymmetric space group $C 2 / c$. The molecular backbone consists of a head formed by the acetamide group, a central part composed by the atoms from $C(2)$ to $C(9)$, and a tail from the chiral $C(10)$ to $C(14)$. The atoms of the first two parts are in a well-defined arrangement, whereas some disorder is observed in the last one. The molecular tail can adopt two structures, differing from one another in $\mathrm{C}(11)$ position. In one of these conformations, $(R, S)_{\mathrm{a}}$, this carbon atom is in the $\mathrm{C}(11 \mathrm{a})$ position, and in the other, $(R, S)_{\mathrm{b}}$, it is in the $\mathrm{C}(11 \mathrm{~b})$ position. The relative occurrence of these structures is $57 \%$ of $(R, S)_{\mathrm{a}}$ to $43 \%$ of $(R, S)_{\mathrm{b}}$. Despite the $\mathrm{C}(11)$ positional difference, a unique structure is shown by the isopropylamino group. Each enantiomer statistically occupies an $R$ and $S$ configuration.

Neglecting a small deviation of the $\mathrm{C}(9)$, all non-hydrogen atoms of the central molecular segment are in the plane defined by the aromatic ring. $\mathrm{C}(1), \mathrm{O}(1)$, and $\mathrm{N}(1)$ of the amide group are in another plane, making an angle of $86.1^{\circ}$ with the former. The angles of the bonds centered at $\mathrm{N}(1)$ are close to $120^{\circ}$, and the sum of the angles with $\mathrm{C}(1)$ as common vertex is also $360^{\circ}$, although small differences are observed among them.

The molecules are aligned along the $a$ axis. They are oriented head to head, and the heads are linked by hydrogen bonds along both the $a$ - and $c$-axis, forming a ladder as seen in Figure 3 . Each hydrogen atom of the acetamide group is shared with an oxygen atom of a symmetry-related acetamide group, delineating rings of eight atoms, with graph-designator $\mathrm{R} 2,2(8)$. $\mathrm{H}(3)$ is

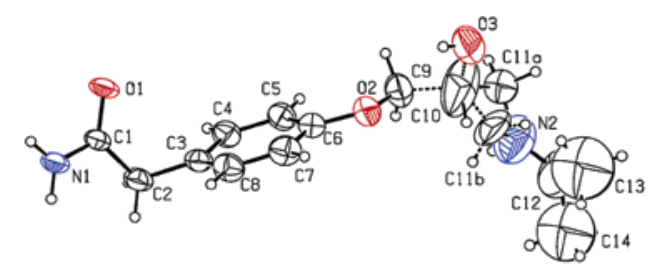

$(R, S)$-atenolol

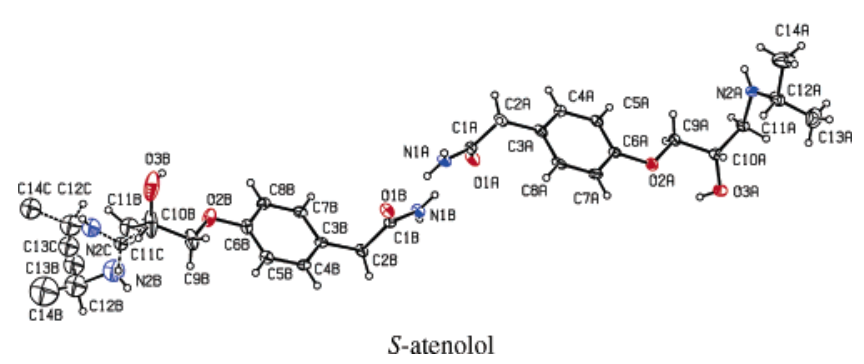

Figure 2. $(R, S)$ - and $S$-atenolol ORTEPII drawing. The ellipsoids are drawn at the $30 \%$ probability level for clarity reasons. 
Table 2. Bond Lengths, Bond Angles, and Dihedral Angles for the Molecular Conformation in the Solid State and after Optimization at the HF/6-31G* Level of Theory

\begin{tabular}{|c|c|c|c|c|c|c|c|c|c|c|}
\hline & \multicolumn{2}{|c|}{$(R, S)_{\mathrm{a}}$} & \multicolumn{2}{|c|}{$(R, S)_{\mathrm{b}}$} & \multicolumn{2}{|l|}{$S_{\mathrm{a}}$} & \multicolumn{2}{|l|}{$S_{\mathrm{b}}$} & \multicolumn{2}{|l|}{$S_{\mathrm{c}}$} \\
\hline & crystal & relaxed & crystal & relaxed & crystal & relaxed & crystal & relaxed & crystal & relaxed \\
\hline \multicolumn{11}{|c|}{ Bond Lengths/Å } \\
\hline $\mathrm{C}(1)-\mathrm{O}(1)$ & $1.238(2)$ & 1.200 & $1.238(2)$ & 1.199 & $1.251(3)$ & 1.200 & $1.253(3)$ & 1.199 & $1.253(3)$ & 1.199 \\
\hline $\mathrm{C}(1)-\mathrm{N}(1)$ & $1.315(3)$ & 1.351 & $1.315(3)$ & 1.353 & $1.324(4)$ & 1.351 & $1.344(4)$ & 1.351 & $1.344(4)$ & 1.351 \\
\hline $\mathrm{N}(2)-\mathrm{C}(11)$ & $1.439(6)$ & 1.457 & $1.491(7)$ & 1.453 & $1.494(4)$ & 1.453 & $1.637(10)$ & 1.446 & $1.204(12)$ & 1.448 \\
\hline $\mathrm{N}(2)-\mathrm{C}(12)$ & $1.377(8)$ & 1.460 & $1.377(8)$ & 1.463 & $1.506(4)$ & 1.461 & $1.633(12)$ & 1.457 & $1.592(15)$ & 1.457 \\
\hline \multicolumn{11}{|c|}{ Bond Angles/ ${ }^{\circ}$} \\
\hline $\mathrm{O}(1)-\mathrm{C}(1)-\mathrm{N}(1)$ & 121.49(19) & 122.5 & $121.49(19)$ & 122.5 & $122.9(3)$ & 122.5 & $121.6(2)$ & 122.5 & $121.6(2)$ & 122.5 \\
\hline $\mathrm{C}(2)-\mathrm{C}(1)-\mathrm{O}(1)$ & 121.04(18) & 120.3 & $121.04(18)$ & 120.8 & $119.6(2)$ & 120.2 & $120.7(2)$ & 120.3 & $120.7(2)$ & 120.2 \\
\hline $\mathrm{C}(2)-\mathrm{C}(1)-\mathrm{N}(1)$ & $117.47(16)$ & 117.2 & $117.47(16)$ & 116.6 & $117.5(2)$ & 117.2 & $117.7(2)$ & 117.2 & $117.7(2)$ & 117.3 \\
\hline $\mathrm{C}(11)-\mathrm{N}(2)-\mathrm{C}(12)$ & $122.4(5)$ & 116.9 & $100.7(5)$ & 117.8 & $114.6(2)$ & 116.8 & $128.3(6)$ & 122.4 & 108.6(9) & 115.9 \\
\hline \multicolumn{11}{|c|}{ Torsion Angles $/^{\circ}$} \\
\hline $\mathrm{N}(1)-\mathrm{C}(1)-\mathrm{C}(2)-\mathrm{C}(3)$ & $-141.2(2)$ & -18.8 & $-141.2(2)$ & -18.8 & $135.0(3)$ & 16.9 & $-142.1(2)$ & -19.9 & $-142.1(2)$ & -17.4 \\
\hline $\mathrm{O}(1)-\mathrm{C}(1)-\mathrm{C}(2)-\mathrm{C}(3)$ & $39.4(3)$ & 163.9 & $39.4(3)$ & 163.9 & $-44.7(4)$ & -165.6 & $38.7(4)$ & 162.9 & $38.7(4)$ & 165.2 \\
\hline $\mathrm{C}(1)-\mathrm{C}(2)-\mathrm{C}(3)-\mathrm{C}(4)$ & $-102.7(2)$ & -85.2 & $-102.7(2)$ & -85.2 & 104.8(3) & 85.9 & $-105.3(3)$ & -84.7 & $-105.3(3)$ & -85.7 \\
\hline $\mathrm{C}(7)-\mathrm{C}(6)-\mathrm{O}(2)-\mathrm{C}(9)$ & $173.6(2)$ & 179.9 & $173.6(2)$ & -179.0 & $-171.0(2)$ & -179.9 & $-178.2(3)$ & 179.5 & $-178.2(3)$ & -179.8 \\
\hline $\mathrm{C}(6)-\mathrm{O}(2)-\mathrm{C}(9)-\mathrm{C}(10)$ & $-171.4(2)$ & -179.3 & $-171.4(2)$ & 177.1 & $168.7(2)$ & -179.2 & $179.5(3)$ & 177.2 & $179.5(3)$ & 177.8 \\
\hline $\mathrm{O}(2)-\mathrm{C}(9)-\mathrm{C}(10)-\mathrm{O}(3)$ & $-69.4(4)$ & -59.0 & $-69.4(4)$ & -63.9 & $69.8(3)$ & 59.2 & $-60.1(3)$ & -63.3 & $-60.1(3)$ & -59.8 \\
\hline $\mathrm{O}(2)-\mathrm{C}(9)-\mathrm{C}(10)-\mathrm{C}(11)$ & 157.81(18) & -177.7 & $97.0(2)$ & 60.9 & $-169.4(2)$ & 178.0 & $62.8(3)$ & 59.9 & $85.7(5)$ & 65.4 \\
\hline $\mathrm{C}(9)-\mathrm{C}(10)-\mathrm{C}(11)-\mathrm{N}(2)$ & $-75.9(4)$ & -61.6 & $72.6(4)$ & 55.3 & $77.5(3)$ & 63.4 & 79.5(4) & 55.4 & $-174.3(7)$ & 173.9 \\
\hline $\mathrm{O}(3)-\mathrm{C}(10)-\mathrm{C}(11)-\mathrm{N}(2)$ & $151.5(4)$ & 177.5 & $-123.5(5)$ & -180.0 & $-159.9(2)$ & -175.5 & $-156.7(4)$ & 179.0 & $-35.3(10)$ & -61.5 \\
\hline $\mathrm{C}(10)-\mathrm{C}(11)-\mathrm{N}(2)-\mathrm{C}(12)$ & $-101.5(6)$ & -110.5 & $156.9(4)$ & 152.9 & $70.0(3)$ & 89.7 & $151.0(6)$ & 84.0 & $147.4(9)$ & 170.3 \\
\hline
\end{tabular}

donated by $\mathrm{O}(3)$ to $\mathrm{N}(2)$ of a translated molecule (along $b$ ), thus linking the molecules along the short axis and delineating a ladder structure, typical of many primary amides with the alternating R2,2(8) and R4,2(8) hydrogen-bonding patterns. The values of atomic distances, bond angles, and torsion angles in the structure of $(R, S)$-atenolol are presented in Table 2, and the characteristic parameters of the classical hydrogen bonds are given in Table 3.

The $\pi$ electron cloud of the aromatic phenyl ring also acts as an acceptor in this structure, joining the molecules along the $c$-axis. The donor $\mathrm{C}(9)$ - ring centroid distance is 3.778(4) $\AA$ with a bond angle of $147.5^{\circ}$ and the deviation of the shared hydrogen $9.4^{\circ}$ from the ring plane perpendicular. These values are within the geometrical requirements for an effective bond. ${ }^{14-16}$ Such an interaction can be considered as a weak hydrogen bond, provided the donor is an acidic group. ${ }^{15}$ The Mulliken charge distribution suggest a slightly higher acidic character of $\mathrm{C}(9)-\mathrm{H}$ than that manifested by the other $\mathrm{C}-\mathrm{H}$ groups, an argument in favor of the contribution of this interaction in $(R, S)$-atenolol structure stabilization. ${ }^{17-19}$

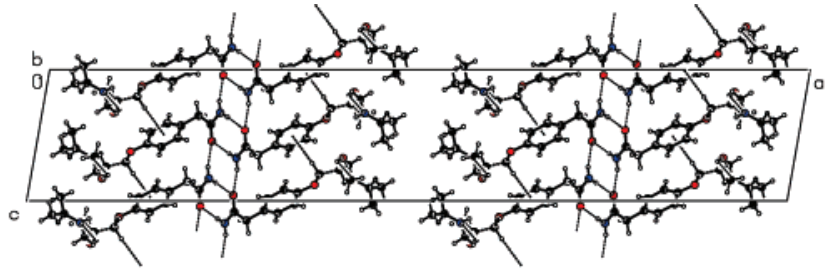

$(R, S)$-atenolol

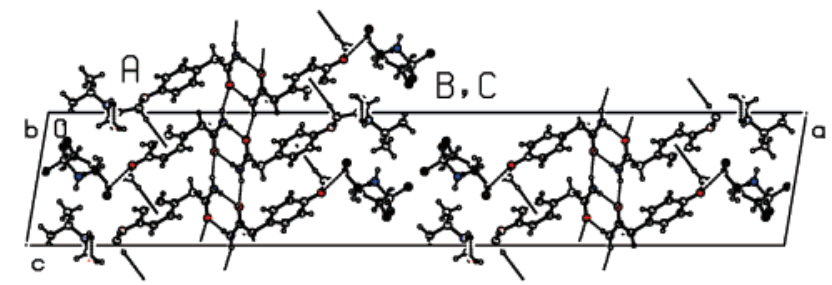

$S$-atenolol

Figure 3. Packing diagram of $(R, S)$ - and $S$-atenolol projected along the $b$-axis. Intermolecular hydrogen bonds as dashed lines.
Table 3. Interatomic Distances and Angles Related to Intermolecular Hydrogen Bonding

\begin{tabular}{|c|c|c|c|c|}
\hline $\mathrm{D}-\mathrm{H} \cdots \mathrm{A}$ & $\begin{array}{c}\mathrm{D} \cdots \mathrm{A} \\
(\AA)\end{array}$ & $\begin{array}{c}\mathrm{H} \cdots \mathrm{A} \\
(\AA)\end{array}$ & $\begin{array}{c}\mathrm{D}-\mathrm{H} \cdots \mathrm{A} \\
(\mathrm{deg})\end{array}$ & symmetry \\
\hline \multicolumn{5}{|c|}{$(R, S)$-atenolol } \\
\hline $\mathrm{N}(1)-\mathrm{H}(1 \mathrm{~A}) \cdots \mathrm{O}(1)$ & $2.900(3)$ & 2.04 & 173.9 & $\begin{array}{c}1 / 2-x, 3 / 2-y \\
1-z\end{array}$ \\
\hline $\mathrm{N}(1)-\mathrm{H}(1 \mathrm{~B}) \cdots \mathrm{O}(1)$ & $2.884(3)$ & 2.06 & 161.5 & $x, 1-y,-1 / 2+z$ \\
\hline $\mathrm{O}(3 \mathrm{~A})-\mathrm{H}(3) \cdots \mathrm{N}(2 \mathrm{~A})$ & $2.983(7)$ & 2.49 & 119.7 & $x, 1+y, z$ \\
\hline \multicolumn{5}{|c|}{$S$-atenolol } \\
\hline $\mathrm{N}(1 \mathrm{~A})-\mathrm{H}(1 \mathrm{~A}) \cdots \mathrm{O}(1 \mathrm{~B}, \mathrm{C})$ & $2.932(3)$ & 2.08 & 172.6 & \\
\hline $\mathrm{N}(1 \mathrm{~A})-\mathrm{H}(1 \mathrm{~B}) \cdots \mathrm{O}(1 \mathrm{~B}, \mathrm{C})$ & $2.857(3)$ & 2.05 & 157.3 & $\begin{array}{c}1 / 2-x, 1 / 2+y \\
1-z\end{array}$ \\
\hline $\mathrm{N}(2 \mathrm{~A})-\mathrm{H}(2) \cdots \mathrm{O}(3 \mathrm{~A})$ & $2.776(3)$ & 2.20 & 123.7 & $x, 1+y, z$ \\
\hline $\mathrm{N}(1 \mathrm{~B}, \mathrm{C})-\mathrm{H}(1 \mathrm{~A}) \cdots \mathrm{O}(1 \mathrm{~A})$ & $2.895(3)$ & 2.04 & 175.1 & \\
\hline $\mathrm{N}(1 \mathrm{~B}, \mathrm{C})-\mathrm{H}(1 \mathrm{~B}) \cdots \mathrm{O}(1 \mathrm{~A})$ & $2.851(3)$ & 2.05 & 154.7 & $\begin{array}{l}1 / 2-x,-1 / 2+y \\
\quad-z\end{array}$ \\
\hline
\end{tabular}

A further participation of $\pi$ electrons of the phenyl group may occur by $\pi \cdots \pi$ interactions. According to Sanders et al., ${ }^{20}$ these are really an interaction between the $\pi$ electrons of one group with $\sigma$ electrons of the other aromatic ring. The average centroid distance between neighbors is $5.55 \AA$, and the vector from the centroid of one of the molecules to the centroid of the other makes an angle of $29.7^{\circ}$ with the normal to the plane of the former.

$S$-Atenolol crystallizes in a noncentrossymetric space group $C 2$ with two symmetry-independent molecules. One of these is fully ordered, and the other shows two alternative positions from the chiral center, C(10), onward (Figure 2). Three molecular conformations are observed in the $S$-atenolol: $S_{\text {a }}$ that corresponds to the fully ordered structure, and $S_{b}$ and $S_{c}$, which correspond to the molecules linked to the former. The ratio of $S_{b}$ to $S_{c}$ is 1:0.6. Bearing in mind the structural identity of $S_{b}$ and $S_{c}$ from the molecular head to $C(10)$, distinct atom numbering was used only in the molecular tails.

The head and central parts of the $S$ molecules are similar to those of $(R, S)_{\mathrm{a}}$ or $(R, S)_{\mathrm{b}}$. The differences between the conformations exhibited by the crystals of the racemic and enantiomeric forms lie in the molecular tail structure. These features can be seen in Figure 4, in which the three molecular conformations of the $S$-atenolol crystal are depicted.

The molecules are assembled in the same way in either $S$ - or $(R, S)$-atenolol. The same eight-membered ring elements are seen 
between the molecular heads. In $S$-atenolol hydrogen bonds between the acetamide groups now join symmetry-independent molecules. The molecules are again linked along the $b$-axis but this time with the $\mathrm{N}(2)$ and $\mathrm{O}(3)$ reversing the acceptor-donor roles (Figure 3 ). The geometrical data related to the conformations of $S$-atenolol are given in Table 2, and the values used in the assignment of hydrogen bonds are presented in Table 3.

Besides the hydrogen bonds listed in Table 3 , as in $(R, S)$ atenolol, $\mathrm{C}(9)-\mathrm{H} \cdots \pi$ and $\pi \cdots \pi$ bonds also contribute to intermolecular interactions in $S$-atenolol. In fact, the carbonring centroid distance is 3.765(4) $\AA$ in $S_{a}$, and 3.568(4) $\AA$ in $S_{b}$ or $S_{c}$. The values of the bond angle are $151.1^{\circ}$ in $S_{a}$, and $144.9^{\circ}$ in $S_{b}$ or $S_{c}$. The deviations of the shared hydrogen to the ring plane normal are $8.9^{\circ}$ in $S_{a}$, and $7.7^{\circ}$ in $S_{b}$ or $S_{c}$. Ring centroid distances between interacting $\pi \cdots \pi$ molecules are 5.578(3) $\AA$ with a deviation of centroid-centroid line from ring plane normal of about $29.8^{\circ}$.

A general feature shown by racemic and enantiomeric single crystals is the similarity of the structure of both forms with very similar cell constants. Three types of racemic modifications are usually considered to describe the systems formed by opposite enantiomeric forms: ${ }^{21}$ racemic compound (single solid phase of both enantiomers), racemic mixture or conglomerate (crystal mixture of pure enantiomers), and pseudoracemate (solid solution of the enantiomers). About $90 \%$ of the organic chiral compounds give rise to racemic compounds and $5-10 \%$ to racemic mixtures. The occurrence of pseudoracemate is relatively rare. ${ }^{22}$ This structure was described for DL-carvone, ${ }^{23}$ camphor and some derivatives, ${ }^{24}$ and tazofelone. ${ }^{25}$

Differential scanning calorimetry, powder X-ray diffraction, ${ }^{13} \mathrm{C}$ NMR studies ${ }^{26}$ and differential scanning calorimetry, and powder X-ray diffraction FTIR and $\operatorname{Raman}^{27}$ led to the conclusion that $(R, S)$-atenolol is a solid solution of the enantiomeric forms. These conclusions are in agreement with those drawn from the present study.

A second point that deserves mention is the diversity of molecular conformations taken by the $\mathrm{C}(10)$ to $\mathrm{C}(14)$ molecular fragment. Besides a distinct structure shown by the conformers, further uncertainties in the atomic position are also observed in particular in $(R, S)$-atenolol. A rather similar structural pattern was recently described for tazofelone. ${ }^{25}(R, S)$-Atenolol and $S$-atenolol are examples of conformational isomorphism, that is, single crystal with different conformers. ${ }^{3,28,29}$

Optimization of the Structure of the Atenolol Molecule. The structure of the atenolol molecules retaining the conformation of the solid state were freed to relax at the HF/6-31G* level of theory. The resulting structure corresponds to the molecule free from intermolecular interactions in a minimum potential energy surface close to the solid-state energy conformation. The values of the geometrical parameters of the

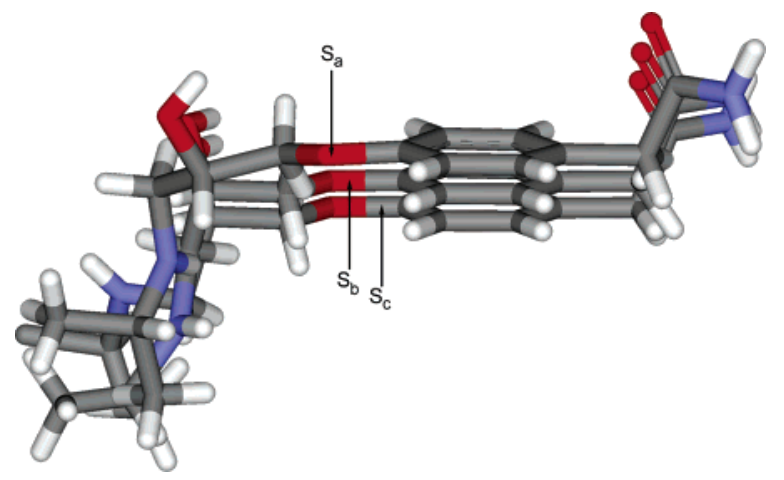

Figure 4. Molecular conformations exhibited by $S$-atenolol.

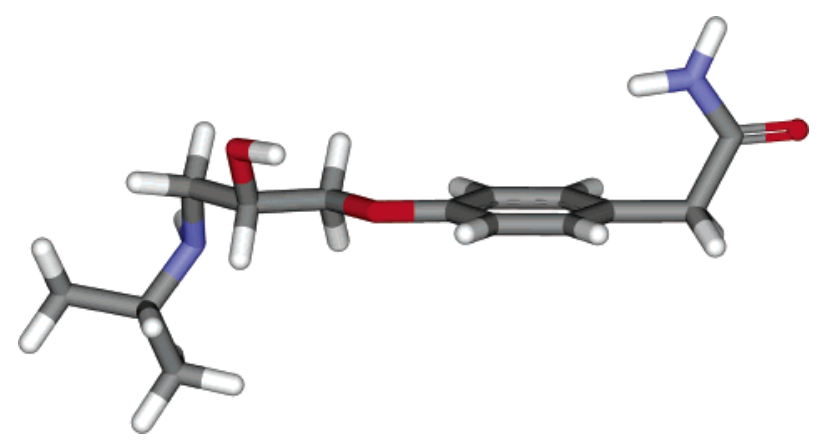

Figure 5. Pattern of the optimized $S_{a}$ molecular structure.

equilibrium conformations obtained are given in Table 2. This table allows the comparison of the atomic distances and bond angles of the conformations shown by X-ray, before and after being optimized.

A significant difference between the molecular conformation in the solid and in the free state is exhibited by the amide group. As the molecules are freed from the intermolecular forces, a $118^{\circ}-122^{\circ}$ rotation around the $\mathrm{C}(1)-\mathrm{C}(2)$ bond takes place, and the amide group acquires a configuration that enables the interaction of one of the $\mathrm{N}(1)-\mathrm{H}$ with the phenyl group. The average atomic distances of $\mathrm{N}(1)$ and $\mathrm{H}(1 \mathrm{~B})$ from the phenyl centroid are 3.80(0) $\AA$ and 3.10(1) $\AA$ for the five molecular types considered, and the $\mathrm{N}(1)-\mathrm{H}(1 \mathrm{~B})$ - phenyl centroid angle is $128.9(1)^{\circ}$, values well within the criteria assigned to the existence of a hydrogen bond between $\mathrm{N}-\mathrm{H}$ as the donor group and the $\pi$ electrons of the phenyl ring as acceptor. ${ }^{14,16,30}$ This type of interaction is quite commonly invoked accounting to the $3 \mathrm{D}$ structure stabilization of protein and other polymeric organic molecules. ${ }^{14,15}$ The conformation adopted by the atenolol molecules in the free state is illustrated in Figure 5.

The hydrogen bond involving the amide group enhances the $\mathrm{sp}^{2}$ hybridization of $\mathrm{C}(1)$ and N(1). Indeed, as in the solid state, the sum of the angles centered at these two atoms in the optimized structure is $360^{\circ}$, but the deviation of each angle from $120^{\circ}$ and of one from another is higher in the latter than in the former. Furthermore, the presence of the hydrogen bonds shortens the $\mathrm{C}(1)-\mathrm{N}(1)$ bond and simultaneously lengthens $\mathrm{C}(1)-\mathrm{O}(1)$. These effects are also observed in small molecules such as acetamide. ${ }^{31,32}$

Knowledge of the energy barrier between the optimized structures $S_{b}$ and $S_{c}$ is important to answer the question about the possibility of transforming one into the other. The calculation was performed at the same level of theory as that used in the structure optimization, and the transition state structure was obtained by the qst 3 method, which gives rise to an imaginary vibration frequency. The transition states of the two structures differ in the $\mathrm{C}(9)-\mathrm{C}(10)-\mathrm{C}(11)-\mathrm{N}(2)$ dihedral, whose value is $112.4^{\circ}$. The barrier level corresponding to the transformation of $S_{b}$ into $S_{c}$ is $11.4 \mathrm{~kJ} / \mathrm{mol}$, and $37.4 \mathrm{~kJ} / \mathrm{mol}$ is the energy required for the inverse process. In conclusion, $S_{b}$ and $S_{c}$ both can be considered stable structural conformations of $S$-atenolol.

\section{Conclusion}

This work provides, for the first time, data on the crystal structure of atenolol. X-ray diffraction of single crystals combined with computational calculations of the molecule, retaining the conformation in the solid state, allow a detailed description of the spatial arrangement of the atoms in the molecules and of these in the crystal lattice.

The hydrogen-bonding network set up by the amide and phenyl group originates quite an ordered molecular structure 
from $C(1)$ to $C(9)$, common to the crystalline form in either the racemic or the homochiral form. The rest of the molecule adopts several conformations: some have close energy values, indiscriminated by X-rays, and others are distinct structures. Both the racemic atenolol and the $S$-atenolol crystals display distinct molecular conformations from $\mathrm{C}(9)$ to the molecule terminal isopropyl. All the structures to some extent exhibit a certain disordered state.

The conformational isomorphism in molecules like these we are dealing with occurs when molecular segments are flexible enough and packing allows a different structure. It should thus be expected to be quite a common phenomenon in solid organic chemistry in molecules with a medium or large backbone.

Acknowledgment. R.A.E.C. thanks the PRODEP III Project 05.03/C/00206.012/03 for financial support.

Supporting Information Available: The fractional atomic coordinates, displacement parameters, and other supplementary data have been deposited at the Cambridge Crystallographic Data Centre (CCDC No. 602653 for $(R, S)$-atenolol and No. 602654 for $S$-atenolol). X-ray crystallographic information files (CIF) are available free of charge via the Internet at http://pubs.acs.org.

\section{References}

(1) Grant, D. J. W. In Polymorphism in Pharmaceutical Solids; Brittain, H. G.; Dekker, M., Eds.; Marcel Dekker: New York, 1999; Vol. 95.

(2) Byrn, S. R.; Pfeiffer, R. R.; Stowell, J. G. Solid-State Chemistry of Drugs; SSCI Inc.: West Lafayette, IN, 1999; Chapter 10.

(3) Bernstein, J. Polymorphism in Molecular Crystals; Clarendon Press: Oxford, 2002

(4) Hilfiker, R. Polymorphism In the Pharmaceutical Industry; John Wiley and Sons Inc: Weinheim, 2006; Chapter 10

(5) Bernstein, J. Polymorphism in Molecular Crystals; Clarendon Press: Oxford, 2002; Chapter 3.

(6) Bose, D. S.; Narsaiah, A. V. Bioorg. Med. Chem. 2005, 13, 627.

(7) Mosby's Drug Consult. http://www.mosbysdrugconsult.com/DrugConsult/Top_200/. This list is based on data from Scott-Levin, Newton, PA (02/21/06).

(8) Pearson, A.; Gaffney, T.; Walle, T.; Privitera, P. J. Pharmacol. Exp. Ther. 1989, 250, 759 .

(9) Spek, A. L. HELENA. CAD-4 Data Reduction Program; University of Utrecht, The Netherlands: Utrecht, 1997.

(10) Bruker SMART (Version 5.059) and SAINT (Version 6.01); Bruker AXS Inc.: Madison, Wisconsin, 1997.

(11) Sheldrick, G. M. SHELXS97 and SHELXL97; Institüt für Anorganische Chemie der Universität: Gottingen, Germany, 1997.
(12) Frisch, M. J.; Trucks, G. W.; Schlegel, H. B.; Scuseria, G. E.; Robb, M. A.; Cheeseman, J. R.; Zakrzewski, V. G.; Montgomery, J. A.; Stratmann, R. E.; Burant, J. C.; Dapprich, S.; Millam, J. M.; Daniels, A. D.; Kudin, K. N.; Strain, M. C.; Farkas, O.; Tomasi, J.; Barone, V.; Cossi, M.; Cammi, R.; Mennucci, B.; Pomelli, C.; Adamo, C.; Clifford, S.; Ochterski, J.; Petersson, G. A.; Ayala, P. Y.; Cui, Q.; Morokuma, K.; Malick, D. K.; Rabuck, A. D.; Raghavachari, K.; Foresman, J. B.; Cioslowski, J.; Ortiz, J. V.; Baboul, A. G.; Stefanov, B. B.; Liu, G.; Liashenko, A.; Piskorz, P.; Komaromi, I.; Gomperts, R.; Martin, R. L.; Fox, D. J.; Keith, T.; Al-Laham, M. A.; Peng, C. Y.; Nanayakkara, A.; Challacombe, M.; Gill, P. M. W.; Johnson, B.; Chen, W.; Wong, M. W.; Andres, J. L.; Gonzalez, C.; HeadGordon, M.; Replogle, E. S.; Pople, J. A. Gaussian 98, revision A.9. Gaussian, Inc: Pittsburgh, PA, 1998.

(13) Johnson, C. K. ORTEPII. Report ORNL-5138; Oak Ridge National Laboratory, Tennessee, 1976.

(14) Steiner, T.; Koellner, G. J. Mol. Biol. 2001, 305, 535.

(15) Desiraju, G. R.; Steiner, T. The Weak Hydrogen Bond - In Structural Chemistry and Biology, IUCr Monographs on Crystallography 9; Oxford University Press: Oxford, 1999; pp 135-158.

(16) Malone, J. F.; Murray, C. M.; Charlton, M. H.; Docherty, R.; Lavery, A. J. J. Chem. Soc. Faraday Trans. 1997, 93, 3429.

(17) Umezawa, Y.; Tsuboyama, S.; Takahashi, H.; Uzawat, J.; Nishiot, M. Tetrahedron 1999, 55, 10047.

(18) Munshi, P.; Venugopala, K. N.; Jayashree, B. S.; Row, T. N. G. Cryst. Growth Des. 2004, 4, 1105.

(19) Nishio, M. Cryst. Eng. Comm. 2004, 6, 130.

(20) Hunter, C. A.; Sanders, J. K. M. J. Am. Chem. Soc. 1990, 112, 5525.

(21) Mitchell, A. G. J. Pharm. Pharmaceut. Sci. 1998, 1, 8.

(22) Eliel, E. L.; Wilen, S. H. Stereochemistry of Organic Compounds; John Wiley and Sons Inc: New York, 1994; p 159.

(23) Sane, J.; Rius, J.; Calvet, T.; CuevasDiarte, M. A. Acta Crystallogr. 1997, B53, 702 .

(24) Jacques, J.; Collet, A.; Wilen, S. Enantiomers, Racemates, and Resolutions; John Wiley and Sons: New York, 1994; p 106.

(25) Huang, J.; Chen, S.; Guzei, I. A.; Yu, L. J. Am. Chem. Soc. 2006 128,11985

(26) Li, Z. J.; Zell, M. T.; Munson, E. J.; Grant, D. J. W. J. Pharm. Sci. 1999, 88, 337 .

(27) Burger, A.; Rollinger, J. M.; Lindner, W. Pharmazie 1999, 54, 47.

(28) Zhang, Z.-Q.; Uth, S.; Sandman, D. J.; Foxman, B. M. J. Phys. Org. Chem. 2004, 17, 769.

(29) Bilton, C.; Howard, J. A. K.; Madhavi, N. N. L.; Nangia, A.; Desiraju, G. R.; Allen, F. H.; Wilson, C. C. Chem. Commun. 1999, 1675.

(30) Cheng, J. G.; Kang, C. M.; Zhu, W. L.; Luo, X. M.; Puah, C. M.; Chen, K. X.; Shen, J. H.; Jiang, H. L. J. Org. Chem. 2003, 68, 7490

(31) Samdal, S. J. Mol. Struct. 1998, 440, 165.

(32) Takeuchi, H.; Sato, M.; Tsuji, T.; Takashima, H.; Egawa, T.; Konaka, S. J. Mol. Struct. 1999, 486, 175.

CG0601857 